\title{
Recommendations for the development of the National Network for Innovation and Technology Transfer (ReNITT) performances
}

\author{
Narcisa Melania TĂNASE \\ Ministry of Research and Innovation, Bucharest, Romania \\ narcisa.tanase@research.gov.ro \\ Mihaela CARAMIHAI (GUDA) \\ Ministry of Research and Innovation, Bucharest, Romania \\ mihaela.guda@research.gov.ro \\ Alexandru MARIN \\ University POLITEHNICA from Bucharest, Bucharest, Romania \\ alexandru.marin@upb.ro \\ Laura BOANȚĂ \\ University POLITEHNICA from Bucharest, Bucharest, Romania \\ laura.boanta@upb.ro \\ Anca Alexandra PURCĂREA \\ University POLITEHNICA from Bucharest, Bucharest, Romania \\ apurcarea@gmail.com
}

\begin{abstract}
The paper analyzes the activity of the National Network for Innovation and Technology Transfer (ReNITT), identifying the problems it faces in the innovation market. The methodology for the analysis implied the consultation, by responding to a questionnaire, of the accredited entities from ReNITT. On the basis of this analyze it were formulated some development recommendations, in order to accelerate the transfer of research results to the market and to increase the level of innovation in SMEs.
\end{abstract}

Keywords: ReNITT Entities, Innovation, Technology Transfer Network, R\&D Marketing.

\section{Introduction}

Innovation is a comprehensive concept, thus its interpretation should not only be focused on research activity. Innovation activity has also features derived from the concept of a knowledge based economy, in connection with eco - innovation (designing the product based on how the used materials will be recycled after the end of the product life cycle), and non-technological or social innovation, which refers to the ability of some people to seize and valorize environmental, social, economic, or political evolutions (Chesbrough, 2003; Öberg \& Alexander, 2018).

In order to cover the whole spectrum of innovation activities, funding must focus primarily on the concept of "product for the market" and the research activity should, to a greater extent, be financed through "top-down" mechanisms, defined by experts gathered in technology platforms. Simultaneously realization of these prerequisites implies the 
alignment of national and European programs to the competitive realities, by creating a "chain" of financing of each link of innovation, from idea to product introduced into the market (Mirtalaie et al., 2017).

\section{Literature review}

Innovation covers a very complex area of a company's business and differs from one firm to another. Determining the degree of innovation at a company level requires the most objective analysis of R\&D activities, intellectual property and patent invention status as well as realized investments, in direct correlation with the performances obtained by the firm, closely related to its productivity and profitability (Wang \& Seidle, 2017).

The investments made through the valorization of RDI results aim to increase the economic competitiveness of SMEs through technology transfer, achievable by developing public and private support mechanisms for innovation and technology transfer, in all regions of Romania, in line with the principles of smart specialization. Thus, in 2003 at national level, in order to accelerate the process of technology / knowledge transfer to society, it was created the National Network for Innovation and Technology Transfer (ReNITT), by the Romanian Government Decision no. 406/2003.

ReNITT aims to increase the visibility of $R \& D$ organizations and improve the competitiveness of SMEs, by developing knowledge and technology transfer services. According to the Romanian Government Decision no. 406/2003, the types of entities for innovation and technological transfer were established as follows:

1. Technology Transfer Centers - have the purpose of training to facilitate technology transfer and intellectual property protection, conducting market, feasibility and technical studies, technological audits, advice on accessing national / European / structural funds;

2. Technological and Business Incubators - have the purpose to facilitate the initiation and development of innovative, technology based new firms, stimulating innovation and technological transfer for the purpose of introducing the research results into the economic circuit, and increasing the quality and competitiveness of products, processes and services, with implicit support for sustainable regional development strategies;

3. Technology Information Centers - have the purpose of disseminating the results of R\&D activities among SMEs, by providing services for valorization of research results, and providing qualified training in specific areas of interest;

4. Liaison offices with the industry - have the object of activity to establish, maintain and expand the links between the suppliers of research and development results and the socio-economic environment / economic agents, in order to facilitate the technological transfer.

Infrastructure entities are evaluated by the Ministry of Research and Innovation (MCI) in order to obtain the title of "Infrastructure Entity"; the evaluation comprises several process stages, i.e. reviewing and evaluating the documentation requested by $\mathrm{MCI}$; provisional authorization; audit for accreditation and granting the title. It should be emphasized that both provisional authorization and accreditation are granted by field of activity, according to the economical domains in which the applicant operates. 


\section{Methodology}

The results of activities developed by ReNITT entities were analyzed by means of a study carried out in a research project, funded by the National Authority for Scientific Research, currently the Ministry of Research and Innovation (Hadăr et al., 2016).

The target group consists of members of the ReNITT network: Technological Transfer Centers (CTT), Technological Information Centers (CIT) and Technology and Business Incubators (ITA), no Liaison offices with the industry being identified as functioning in Romania.

The data used for analysis were gathered with the help of a questionnaire, specially designed for the target group, information being gathered and identifying the issues faced by ReNITT entities in their current activities. In fact, the questionnaire addressed aspects related to the type of cooperation partnerships, the $\mathrm{R} \& \mathrm{D}$ results and their capitalization capabilities, the impact of innovation activities on the economic environment, investment breadth in ITT activities, staff recruitment problems, extent to which staff competencies respond to current ITT needs, the need to improve the ITT staff competencies, difficulties in securing existing human resource capabilities, factors that affect innovative activity, ITT activity domains and regional smart specialization priorities addressed by ReNITT entities, correlation between the demand of enterprises, public institutions etc. and the specialized ReNITT offer, ways of increasing the contribution of innovation to regional development in the period 2015-2020.

The ReNITT Entities Survey was addressed to managers or to persons from the management, who had an overview of the current situation regarding the activity and the problems faced by the ITT entity in the innovation market. Sending and collecting questionnaires to / from the target group was done by e-mail facilities. The period for completing the questionnaires was 18.09.2015 - 15.10.2015.

Data processing was performed using the IRECSond software (Marin et al., 2015), which allows data upload, validation and processing. Data processing involved the following successive steps: Data entry and validation at screen level; Automatic control and edit the list of errors; Entering corrections and resuming automatic control; Automatic data processing and final data tables filling.

\section{Results and discussions}

94\% of network members have cooperation agreements with enterprises or other Innovation and Technology Transfer (ITT) entities. There are 219 cooperation agreements at the level of ReNITT, of which 164 are with organizations / institutions from Romania and 55 with organizations / institutions from other countries. In another terms, the average number of ReNITT collaboration agreements is 6, of which 5 with institutions in Romania and 1 agreement is with institutions from other countries. Although $38 \%$ of the entities have over 47 agreements, majority having only few agreements, it leads to a relatively low level of networking.

The network ReNITT is open to the business environment, but also to the research organizations $(24 \%$ of the agreements are concluded with companies and $11 \%$ with universities or other higher education institutions), but also with openness orientation to the relationship with the public sector and civil society $18 \%$ of the agreements are 
engaged with public authorities, regional development agencies, professional associations, NGOs).

ReNITT treasure consists of 1346 R\&I results, distributed on several categories of results, as presented in Figure 1.

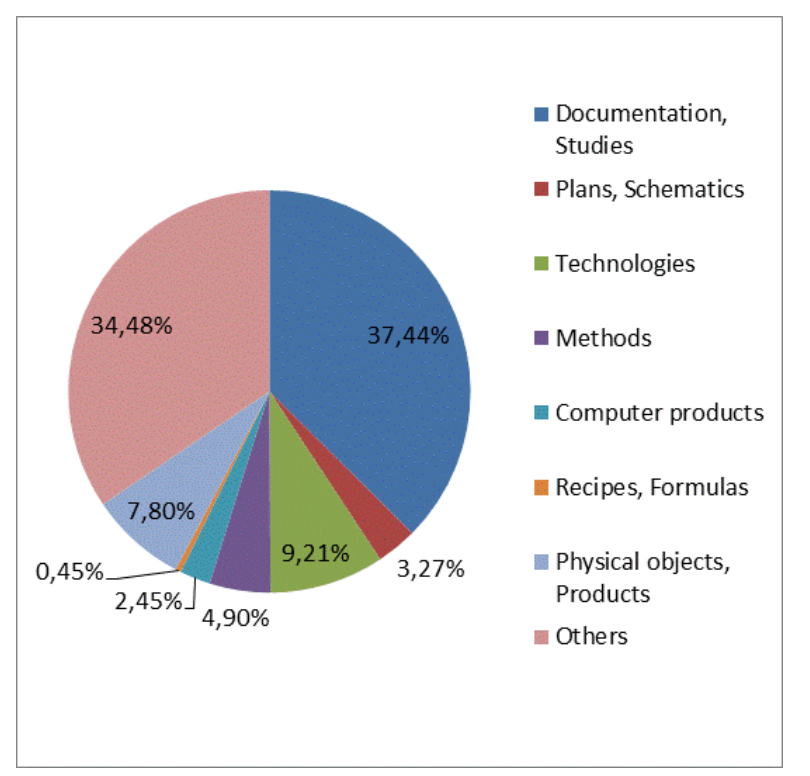

PICBE | 945

Figure 1. Categories of results of ReNITT activities

Source: Authors' own research.

According to the managers of the ITT entities, $12 \%$ of the results have potential to be capitalized by product / technology sales, $48 \%$ by services delivery, $14 \%$ are available for IP licensing, and 26\% having no valorization potential (see Figure 2).

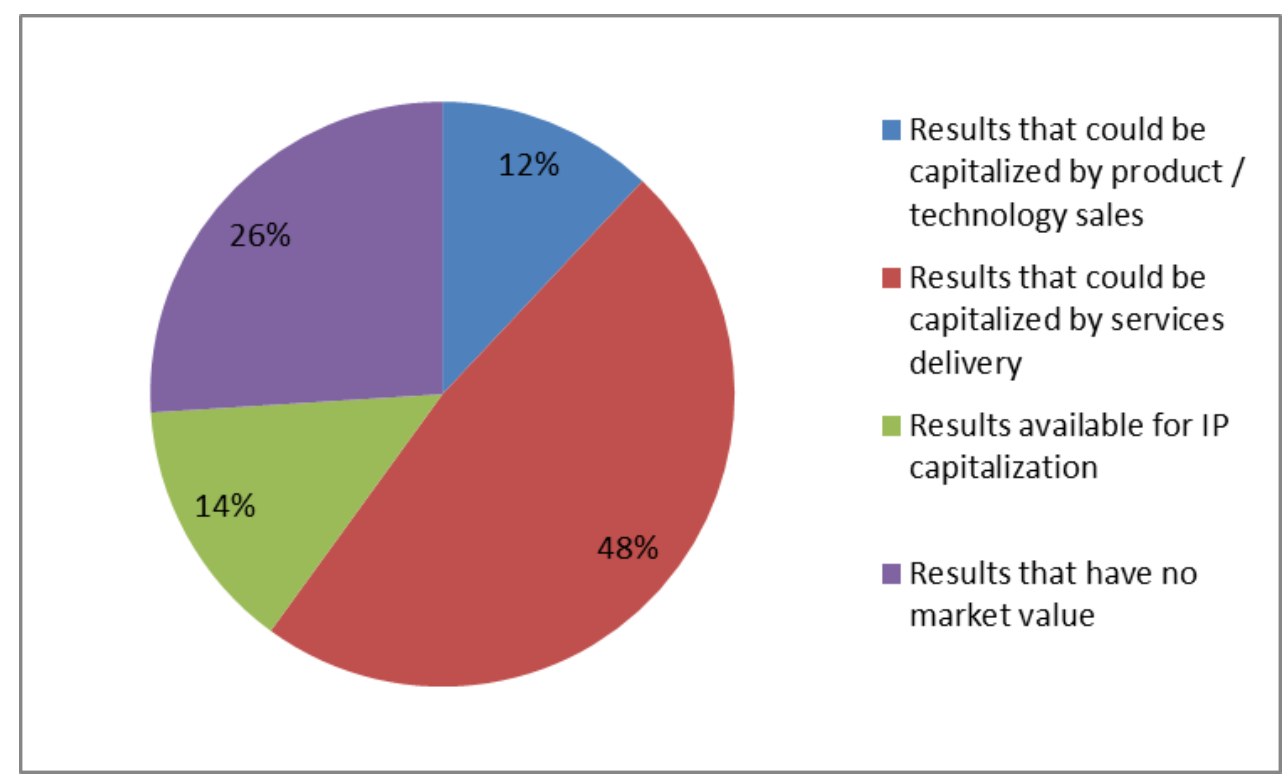

Figure 2. Potential of valorization of ReNITT's results

Source: Authors' own research. 
The national R\&I results transposed into patents (patent applications) or products / technologies aren't found, unfortunately, in the ReNITT treasury, this meaning 769 patents / patent applications and 1444 new products / technologies, obtained between 2007-2010 within the Ideas, Human Resources and Partnerships research programs. The managers of the R\&I entities from Romania appreciated that about $40 \%$ of these results are applicable in the economy, which would represent about 570 products / technologies.

At the level of ReNITT, the law of $1 / 3$ is in force, which can be stated as follows: about $1 / 3$ of the entities (38\%) have R\&D results that can be used by selling the product / technology, including the transferring of industrial / intellectual property rights, while $1 / 3$ of the organizations (32\%) have no results that can be capitalized.

Due to the fact that the majority of the network is more oriented towards services and less to the sale of products / technologies and valorization of IP rights, the impact of ReNITT's activity on the economic environment (based on the "Short Term Balance" - STB criteria, defined as the perceptions on the dynamics of each indicator, not as the real increase / decrease of the respective indicator) was low, as presented in Figure 3.

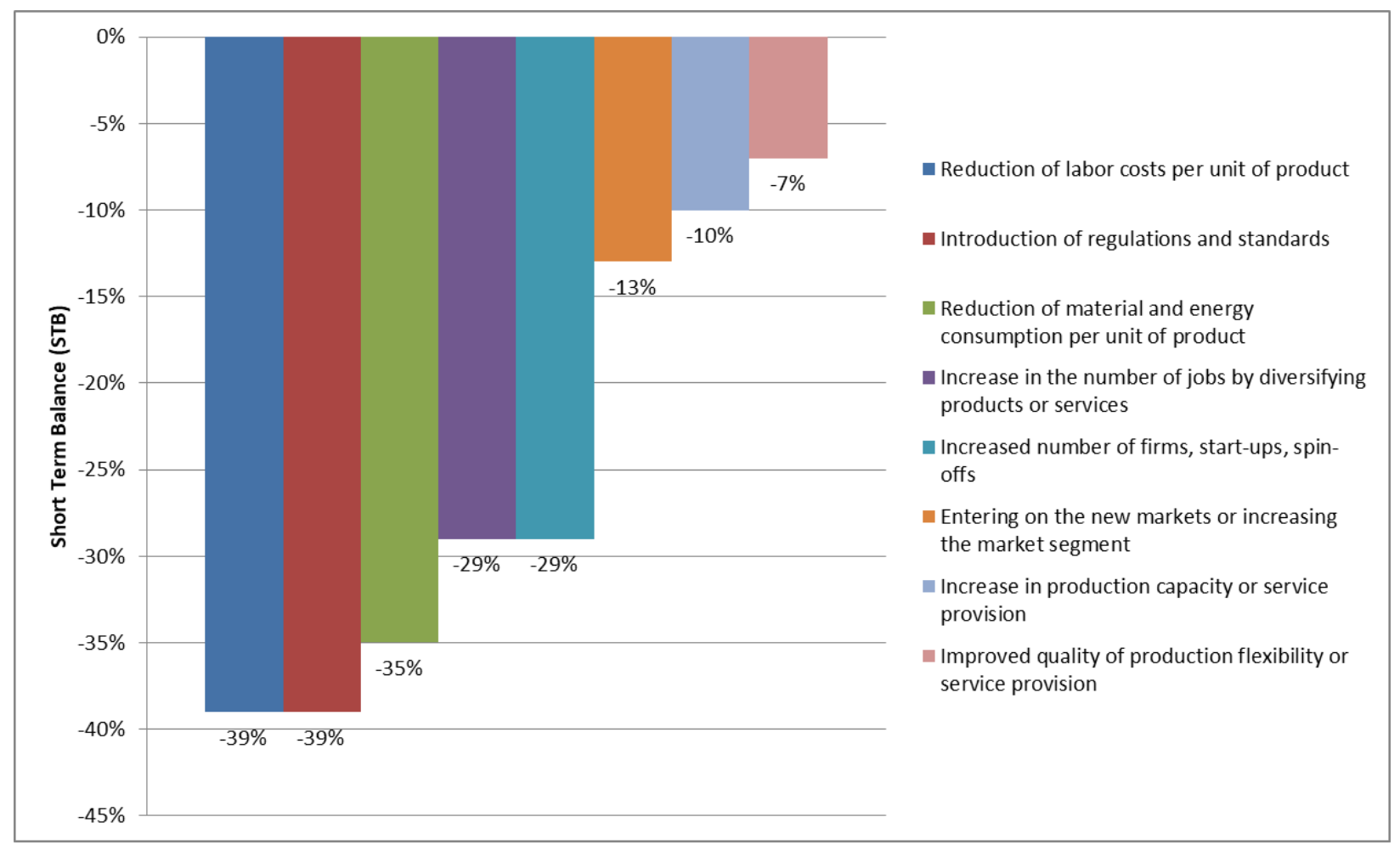

Figure 3. Impact of ReNITT's activity on the economic environment

Source: Authors' own research.

Note: Concerning the "short term balance", we use the following convention: till $\pm 5 \%$ - relative stability, between $\pm(6$ to 15$) \%$ - moderate increase/decrease, between $\pm(16$ to 39$) \%$ - significant increase/decrease, more than $\pm 40 \%$ - important increase/decrease.

Under this perspective, a relative high impact was recorded in expanding the range of goods or services (STB is 13\%), improving the quality of goods or services (STB is $23 \%$ ), improving environmental quality, health and safety (STB is 23\%) (see Figure 4). 


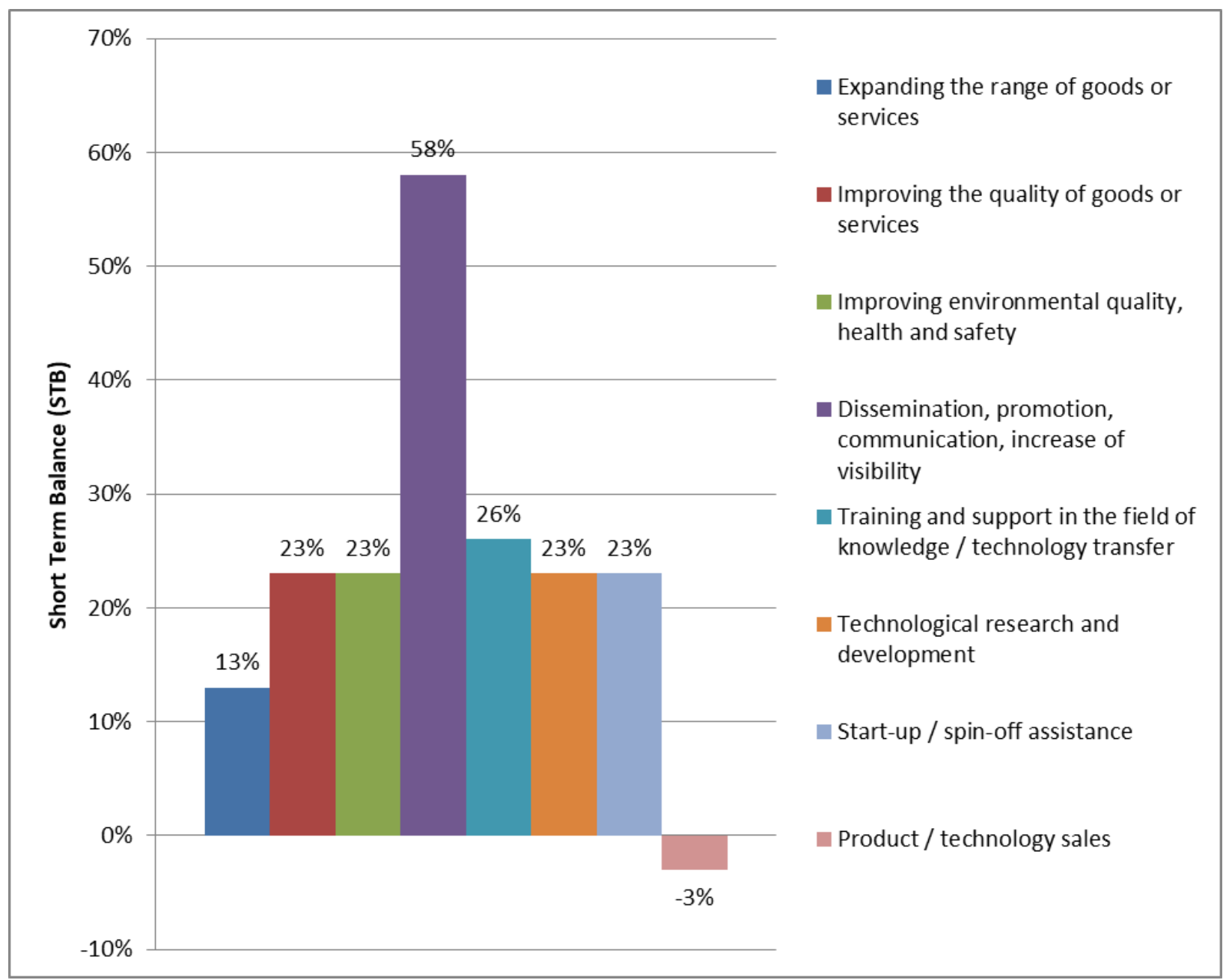

Figure 4. Other positive and relative high impact of ReNITT's activity on the economic environment

Source: Authors' own research.

The situation regarding the activity of the network entities is tributary to a structure of revenues of the network members, which mostly comes from the "host institution" $(31,43 \%), 44,36 \%$ of funds being attracted by national or structural / European programs, $13,68 \%$ of contracts being concluded with the business environment and $10,53 \%$ coming from other sources (see Figure 5). 


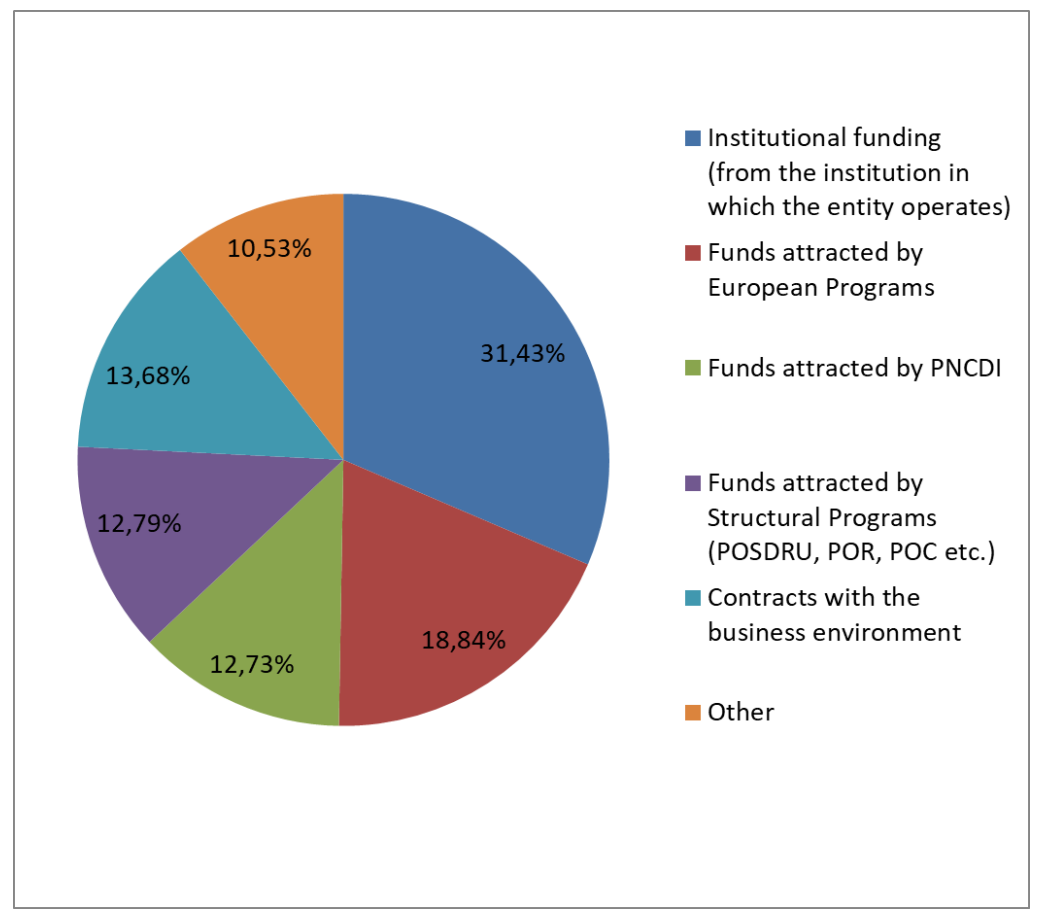

Figure 5. Structure of revenues of the ReNITT's members

Source: Authors' own research.

The reduced share of revenues, coming from the business environment, shows ReNITT's weak interest in market needs, i.e. comparing to Fraunhofer institutes network, where each member must have at least $1 / 3$ of contract revenues from industry.

Given that the number of employees was relatively stable over the past 3 years (STB is $-3 \%$ ), ReNITT faces a lack of qualified staff for the proposed objectives, referred to as percentage of managers having this opinion, as presented in Figure 6.

The smart specialization distribution of expertise in ReNITT framework, under the 2014-2020 National R\&D Strategy, is presented in Figure 7.

The "short term balance" between the offer of ReNITT entities, within the smart specialization domains, and the market demand for their services / products reveals the situation presented in Figure 8, and in an aggregated description as follows: Over-capacity for bio-economy (agro-food, bioenergy-biogas, biomass, biofuel, medicine science), demand is lower than the offer (STB between $-25 \%$ and -8\%); Under-capacity for information and communication technologies, space and security (information and security technologies, security, space), market demand being higher than the offer (STB between $+16 \%$ and + 42\%); Over-capacity for energy, environment and climate change (energy, intelligent systems, smart city), demand is lower than the offer (STB between -16\% and -12\%); Overcapacity for advanced technologies and materials (transport equipment, equipment for production of bio-resources, depollution technologies, materials), the demand being lower than the offer (STB between $-57 \%$ and -14\%); Under-capacity for health (diagnostics, therapy, pharmacology and toxicology, development of new active substances), market demand being higher than the offer (STB between $+7 \%$ and $+33 \%$ ). 


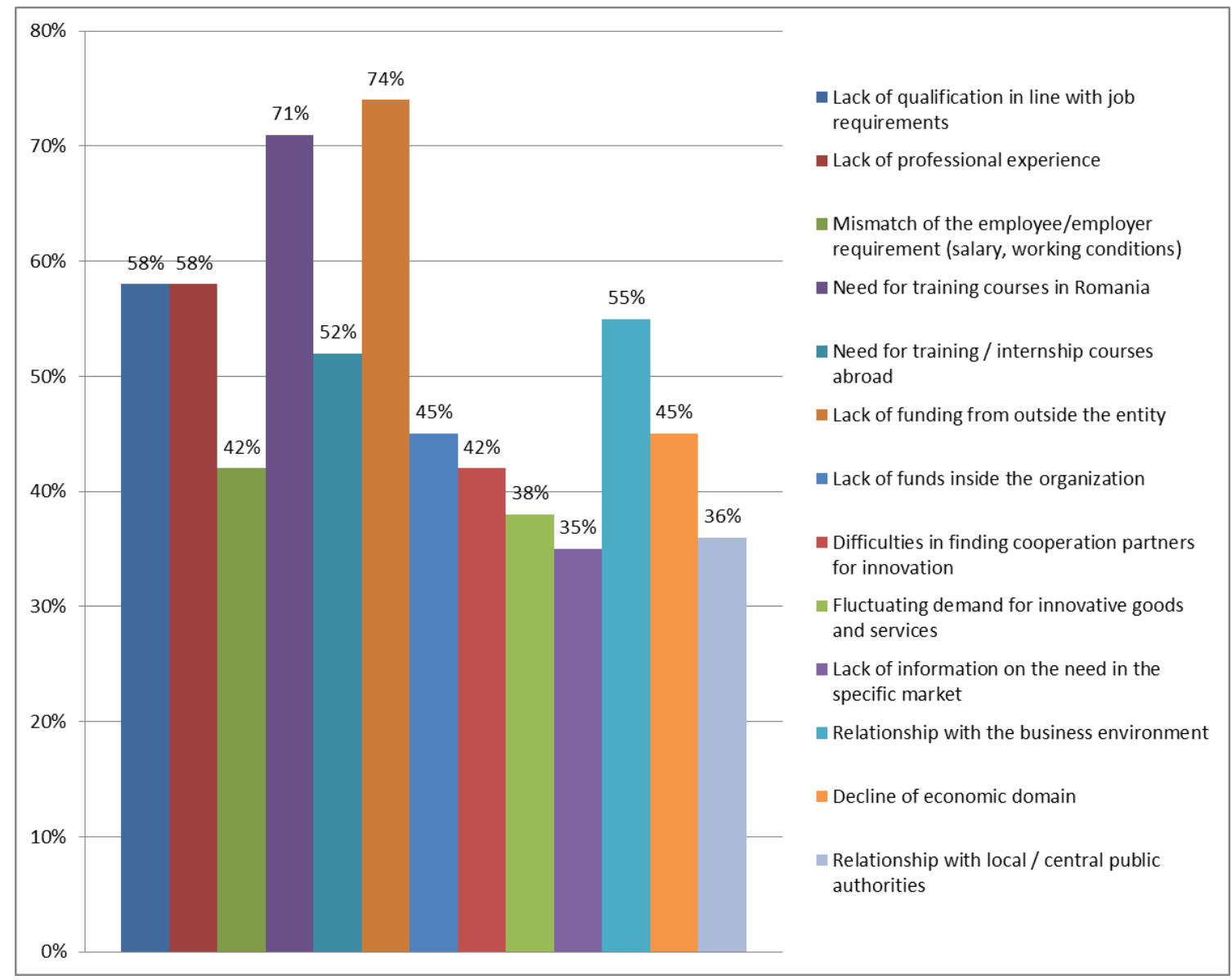

Figure 6. ReNITT's entities manager opinion on major difficulties and innovation barriers Source: Authors' own research.

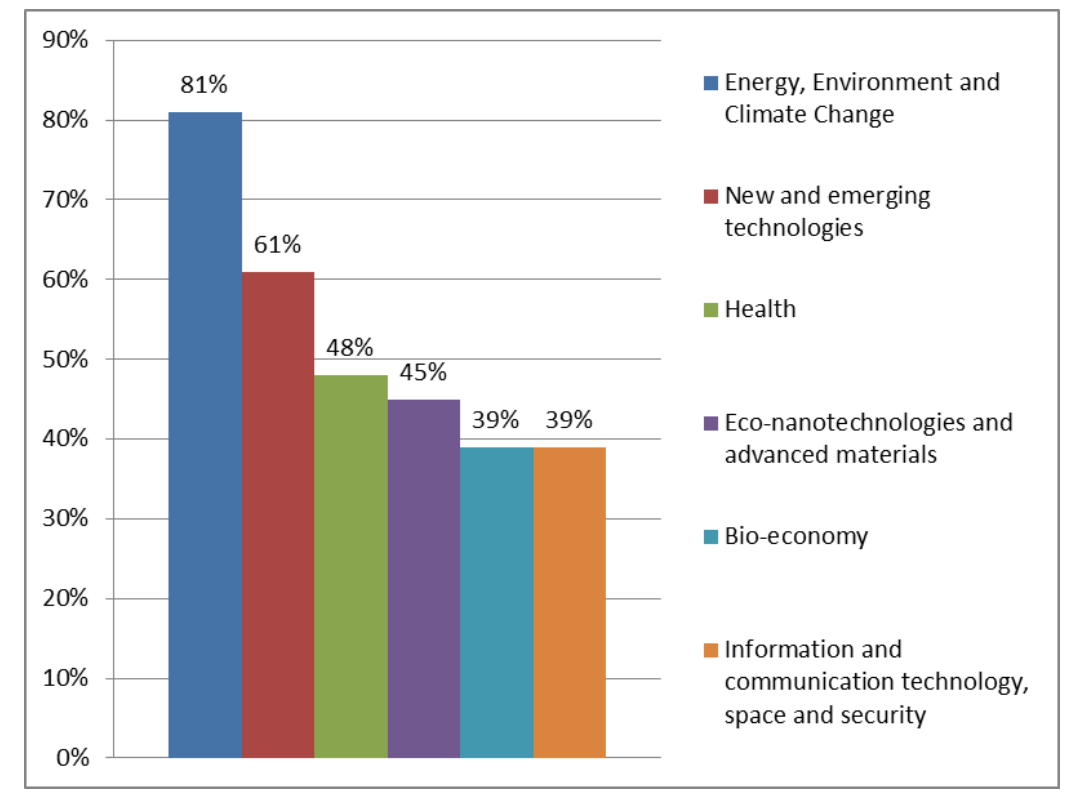

Figure 7. Smart specialization distribution of expertise in ReNITT framework

Source: Authors' own research. 


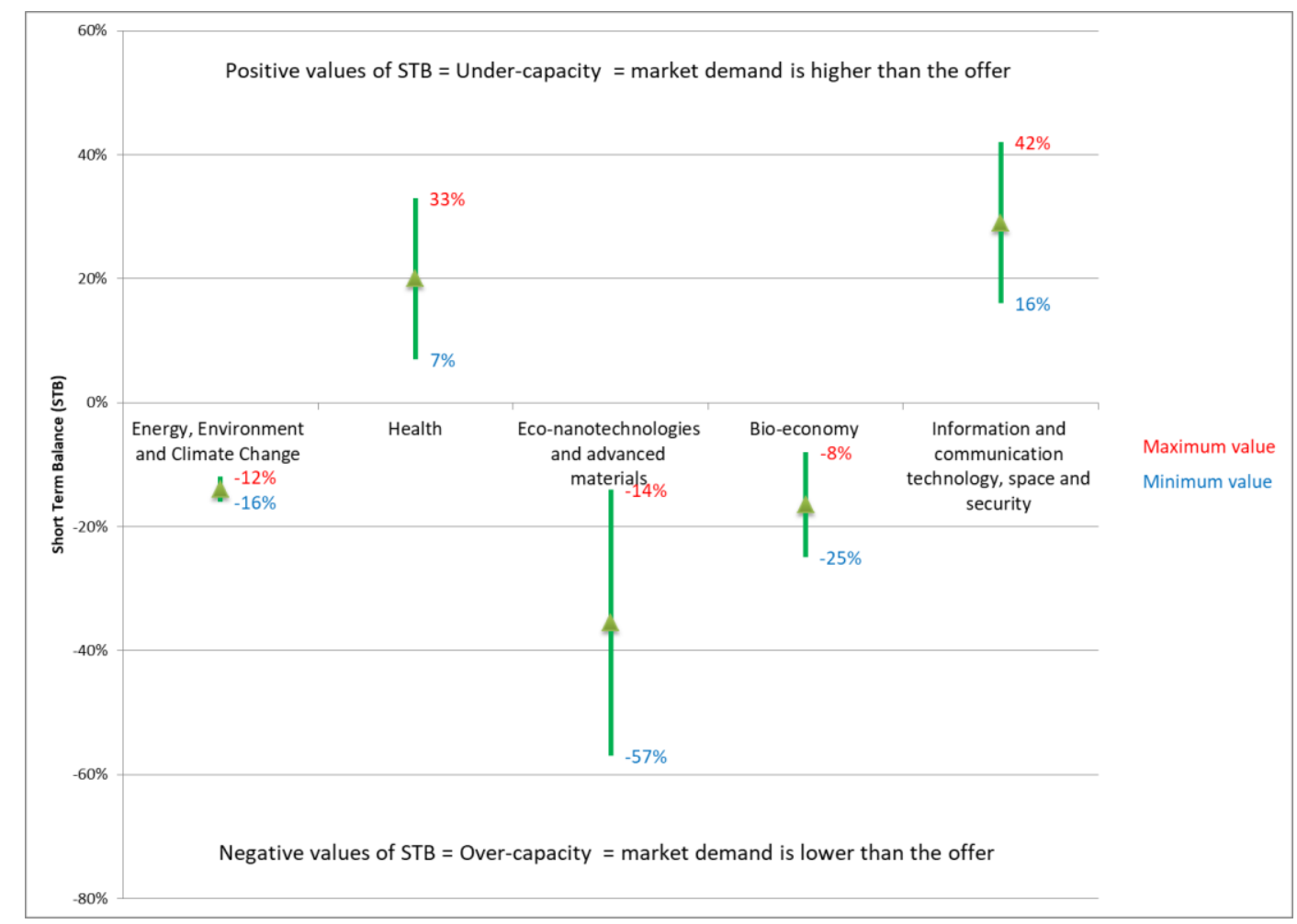

PICBE $\mid 950$

Figure 8. "Short term balance" between the offer of ReNITT entities and the market demand for their services / products

Source: Authors' own research.

As a result of the detailed analysis presented above, some recommendations are necessary, that should be applied at ReNITT network level. Consequently, after all entities will develop a business plan following the same model (Osterwalder et al., 2005; Osterwalder \& Pigneur, 2010) and under the same development framework, some essential steps are advisable:

1. Create an umbrella "entity", in order to actively support the technology transfer centers activities (e.g. marketing, financing sources etc.);

2. Develop an unified internal and external communication strategy; internally, due to Value Propositions, Key Resources chapters from the business model; and externally, by creating a common platform, structured following the Value Propositions essentials, NOT describing each technology transfer center separately, and opened for the customer needs, so they can upload requests online at any time;

3. Board of Trustees must be established, with national and international members (industry, applied research, academia, politics representatives), directly implicated twice a year due to a general meeting and offering FEEDBACK as working instrument, mainly contributing to marketing and economic strategies development, and identifying funding schemes and mechanisms for R\&D\&I activities at network level.

\section{Conclusions}

Romanian innovation and technology transfer infrastructure is inadequate, both as number of specialized entities and as diversification of typology. The greatest share belongs to the technological and business incubators, thanks to the financial support granted through 
programs with external financing. Their main activity is focused on business incubation and, to a lesser extent, on technological incubation.

The regional distribution of the innovation and technological transfer network actors reveals an uneven coverage or Romanian territory, as 27 Romanian counties have no innovation and technological transfer entity; Bucharest is placed in top by concentrating the largest number of entities, on the following positions being placed Galați, Timișoara, Cluj and Brașov.

ITT entities are oriented towards the business environment but also towards the research organizations, as they have agreements with SMEs / companies in their field of activity, universities / higher education institutions, but also being opened to the relationship with public sector and civil society (local / central public authorities, regional development agencies, professional associations, NGOs).

ReNITT is not integrated into a technology transfer network at European level. In compensation, some Entities for Innovation and Transfer of Technology, as members of the ReNITT, are part of other international associative structures, i.e. Romanian Association for Technology Transfer (ARoTT) being member of the largest European network of support for small and medium-sized enterprises (Enterprise Europe Network).

\section{References}

Chesbrough, H.W. (2003). Open innovation: the new imperative for creating and profiting from technology, Harvard Business School Publishing, 60 Harvard Way, Boston, Massachusetts.

Hadăr, A., Marin, A., Costoiu, M., Boanță, L., Cismașu, I. (2016). Financial and SWOT Analysis for a Pilot Model of a TTO from ReNITT, 8th International Conference on Innovations, Recent Trends and Challenges in Mechatronics, Mechanical Engineering and New High-Tech Products Development, ISSN 2247-8388, 130-139.

Marin, A., Boanță, L., Hadăr, A., Badea, D.M., Vlăduț, G., Bucur, D., Ciocănel, B., Ivan, I. (2015). Business Models and Competitive Advantage for Technology Transfer Entities, Romanian Review Precision Mechanics, Optics \& Mecatronics, ISSN 1584 5982, Issue 48, 103-109.

Mirtalaie, M.A., Hussaina, O.K., Farookh, E.C., Hussain,K. (2017). A decision support framework for identifying novel ideas in new product development from crossdomain analysis, Information Systems, Volume 69, 59-80.

Osterwalder, A., Pigneur, Y., Tucci, C. (2005). Clarifying business models: Origins, present, and future of the concept, Communications of the Association for Information Systems, 16 (1), 1-25.

Osterwalder, A., Pigneur, Y. (2010). Business Model Generation: A Handbook for Visionairies, Game Changers, and Challengers, John Wiley \& Sons.

Öberga, C., Alexander, A.T. (2018). The openness of open innovation in ecosystems Integrating innovation and management literature on knowledge linkages, Journal of Innovation \& Knowledge, Retrieved from https://doi.org/10.1016/j.jik.2017.10.005.

Wang, I.K., Seidle, R. (2017). The degree of technological innovation: A demand heterogeneity perspective, Technological Forecasting and Social Change, Volume $125,166-177$. 